\title{
Electronic Record Authenticity in Evidence
}

\author{
Ahmed Fahd Al-Batosh \\ Assistant Professor \\ Ajloun National University
}

\begin{abstract}
With the adoption of the legislator to the principle of functional equivalent, the individuals dealing with electronic transactions became more confident in the electronic record as a tool used to save their procedures that are conducted through the electronic means, and where it has become possible to present electronic record as an evidence in the lawsuit, the judge no longer has the right to refuse the electronic record as an evidence as long as it includes the necessary conditions, and is provided on an electronic mean "which is the reason for which the court rejected the electronic record as evidence "By referring to the Electronic Transactions Law, we find that the legislator graded in the authenticity of the electronic record, by the difference in the type of signature associated with the electronic record until, we reach the state in which the electronic record is not associated with a signature . Therefore, a research will be conducted regarding the authenticity of each record separately, indicating the extent of the evidential power it has, in addition to the research for the adequacy of the provisions that the legislator applied to the electronic record and to what extent the electronic record as a means of. proof is able to dispense with the traditional means of evidence.Until we come to a conclusion that the legislator granted the electronic record th evidential power that it granted to the traditional means, by referring the determination of its evidential power to the general rules. However, we sometimes find that such a matter is not commensurate with the nature that the electronic record enjoys, especially when searching in the electronic commercial record .This study has been divided into two requirements. The first requirement discusses the cases in which the authenticity of the electronic record is presumed and the second requirement discusses the cases in which the authenticity of the electronic record is not presume
\end{abstract}

Keywords: electronic record, electronic signature, unsigned documents, electronic commercial books, the principle of written evidence .

DOI: $10.7176 / \mathrm{JLPG} / 104-05$

Publication date: December $31^{\text {st }} 2020$

\section{Introduction}

The development of electronic technology in the field of communication has led to the emergence of new ways of sending and receiving data, which has led to the establishment of electronic commercial markets through which the buying and selling operations and everything related to it are carried out until we reach the delivery process.

Due to the increased use by the dealers in this way, this has led to the need for electronic means to save these transactions, the saving of which commensurate with its special nature. That is , the possibility of saving it through electronic means and on electronic means. So it becomes possible to review the saved material at any time and refer to it without changing it, it also becomes possible to identify the parties of the electronic transaction and the date of the establishment of the transaction and its sending and receiving .

The customers built confidence in electronic record as a tool to save their transactions and need not to traditional methods of saving, when the legislator recognized and equated between electronic means and traditional means in evidence, as well as when making the submission of the electronic record equals the submission of the original copy of the data as long as its conditions are fulfilled .

This was through the legislature's regulation of electronic transactions and the authenticity of the electronic record in a special law, which is the Electronic Transactions Law No. 85 of 2001, which has been canceled according to the Electronic Transactions Law No. 15 of 2015.

The Jordanian legislator was one of the legislators who singled out a special law for electronic

transactions, methods of saving, and their authenticity in evidence, and the legislator was guided by the UNCITRAL Model Law regarding the Electronic Commerce of the year 1996 issued by the United Nations Commission on International Trade Law .

The electronic record has become a tool for contractors to save their electronic transactions, and they resort to it to save their transactions, and to refer to it in the event that the electronic document is lost or damaged, On the grounds that the electronic record is an electronic archive in which the data of the electronic document are saved, the record ensures the validity of this data and its complete retrieval upon the request of the parties .

The Jordanian legislator stipulated the existence of an electronic signature on the record in order for the record to be used as an evidence, because of the importance of the signature to show the identity of the signing person and the expression of his will and that he is alone in using it . 


\section{Problematic Issues of the Study}

The electronic record is considered one of the most important means that prove the electronic transactions which take place between individuals, and this study focuses on the extent to which the electronic record can be considered as an actual means of evidence, There are three central questions . regarding this issue :

1. To what extent does the legislator recognize the authenticity of the electronic record as a means of proving electronic transactions?

2. Could this method of evidence -for the dealers resorting in civil or commercial electronic transactions- replace the traditional methods of evidence?

3. To what extent are the general evidential rules applicable to evidence in the electronic record, especially in light of the exceptions made by the legislator on the principle of the inadmissibility of crafting the evidence?

\section{The importance of the study}

The importance of the study lies in the emergence of a new means of evidence, which are the electronic records, to prove electronic transactions that have become dealt with more than by traditional methods. The electronic evidence method does not rely on paper documents, unlike the traditional methods.

The importance of the study also appears through showing the conditions that must be available to impart legal authenticity to the electronic record, and the extent of its evidential power, especially in the case that the legislator has considered the presentation of the electronic record of any document or contract in writing, the same in legal results, as the electronic document provided the same, as long as it is possible to view the information from this record, and it can be saved and referred to at any time without changing .

\section{The Previous Studies}

1. Muhammad Rizk Ismael Abu Al-Foul, the authenticity of the audio-visual means of evidence - Master's thesis, 2018, Faculty of Law, Yarmouk University

This thesis dealt with the authenticity of the audiovisual means of evidence, by stating what the audiovisual means are, and the extent to which the electronic signature is related to the audiovisual

means, and showing the legal system of audiovisual means .

This study is similar to my study in showing researches of the authenticity of the electronic signature and the effect of the type of signature on the degree of authenticity of the electronic record. However, this study differs from my study in that the researcher's study focuses on the authenticity of the audiovisual means in evidence, but my study focuses on the authenticity of electronic record in evidence and different degrees of authenticity of the electronic record.

2. BeesanAtif Al-Yassin, the authenticity of the electronic commercial books in evidence in the Jordanian Law- Master's thesis - 2012, Faculty of Law, Amman Arab University , Jordan

This study discusses the authenticity of electronic commercial books, through stating the legal regulation of the keeping of commercial books, and the power of electronic commercial books in evidence .

This study is consistent with my study in talking about the extent of the applicability of general rules in evidence to electronic commercial books, and the sufficiency of these books in evidence, in addition to talking about the authenticity of the electronic commercial books in the interest of the trader and against the interest of the trader .

\section{Study Approach}

The researcher relied in writing this study on the following approaches :

Descriptive approach: by describing the legal texts that regulate the authenticity of the electronic record, and the judicial rulings related to the subject of the study .

Analytical approach: by analyzing legal texts, judicial rulings, and the various sources that were used to collect data and information

\section{The Study Plan}

The first requirement: the presumed authenticity for the electronic record The first section: the electronic record associated with the authenticated signature The second section: the electronic record associated with the protected signature

\section{The second requirement: the non-presumed authenticity for the electronic record}

The first section: the electronic record associated with the simple signature The second section: the unsigned electronic record

The first requirement Presumed authenticity to electronic record

The Jordanian legislator stipulates in the Electronic Transactions Act on the authenticity for the electronic record, and this authenticity for the record derived of its association with the electronic signature, which is considered as 
the method to express the will of the person and his consent of what is stated in the content of the data message that is saved in the electronic record, this connection affects on the integrity of the electronic record, that it shall not be modified or changed .

This information message saved in the electronic record may be an entry, contract, or any document which is created, saved, used, copied, sent, informed or received using the electronic medium. ${ }^{1}$

However, the evidentiary value of this information message varies according to the difference of electronic signature associated with it, the authenticity of the binding electronic record (presumed authenticity) varies according to the signature associated with it, so the electronic record may be a public evidence, and it may be limited in its authenticity to the parties of the transaction only .

The first section: the electronic record associated with the authenticated signature

The legislator stipulates in Article (17 / b) of the Electronic Transactions Law that "the electronic record associated with an electronic signature shall have the same authenticity established for the regular bond .

It is permissible for the parties to an electronic transaction or others to plead using it .

We find that the legislator stipulates that in order for the record to be fully authentic in evidence, it must be accompanied by an authenticated signature, and the signature shall be authenticated according to what the legislator stipulated in the same law in article 16 that the signature is unique to his owner and is different from others, to identify its owner's identity, that the private key is subject to the control of its owner at the time of the signature procedure, and that this signature shall be associated with the record in a way that does not allow any amendment to the electronic record after signing it

The legislator stipulates even more serious conditions to authenticate the electronic signature . That the holder of the electronic signature is required to issue an electronic authentication certificate issued by the authorities that are specified by the law, which are licensed electronic authentication entities in the Kingdom, or an accredited authentication body, or any government entity approved by the Prime Ministry, or the Ministry of Communications, and if the transaction is electronic banking or financial type, the central bank then can grant an electronic authentication certificate. $^{2}$

And the electronic record that holds this authenticity is subject to electronic signature authentication, thus, we find that the legislator elevates this record to the level of the official bond, as he considers it as an authenticity for the concerned parties and the third parties, but this elevation does not upgrade the electronic record associated with the authenticated signature to the level of an official bond, because it is required for the official bond to be issued by a competent employee who has the authority to issue the official bond, ${ }^{3}$ where this electronic record is created and prepared by the parties to the transaction themselves, but thisbond is signed with an authenticated signature . Accordingly, whoever was argued against with an electronic record has the right to deny what is attributed to him. In the event that he denies the signature, the holder of the electronic record must prove the validity of this signature, but in the event that he denies the content of the electronic record, the denier must prove the invalidity of the content of the electronic record, or that he did not send it or didn't charge anyone to send it. ${ }^{4}$

In accordance with the Article (17 / B) of the Electronic Transactions Law itself, the legislator made the electronic record authenticity to others without the need for this electronic record to have a fixed date. The legislator considers that the electronic record shall be associated with authenticated signature to be an authenticity on others, despite considering the electronic record associated with authenticated signature as an authenticity for the regular bond. Thus, the electronic record- associated with authenticated signature- is the highest degree of authenticity that the law grants to the electronic record, being an authenticity for the concerned parties and others .

\section{The second section: the electronic record associated with the protected signature}

The text of Article (17 / A) of the Electronic Transactions Law states that "the electronic record associated with a protected electronic signature shall have the same authenticity as prescribed for the regular bond, and the parties of an electronic transaction may argue using it "

In order for the electronic record to have the authenticity of the ordinary bond it must be associated to a protected signature, and the signature is considered protected according to the text of Article (15) of the same law, with the presence of the following conditions. 1. If the signature holder is singular with it in order to distinguish it from others. 2. If it specifies the identity of the signature holder 3. If the private key is subject to the control of the signature holder at the time of the signature procedure 4. If the electronic record is associated- in a way that does not allow modification -to that electronic record after signing it without any change to that signature

\footnotetext{
${ }^{1}$ See Article (1), Definition of the Electronic Record, Electronic Transactions Law No. (15) for the year (2015), published in the Official Newspaper, page (5292), No. (5341), on 17/05/2015

${ }^{2}$ Article (16), Electronic Transactions Law, previous reference

${ }^{3}$ Article (6), Definition of the Official Bond, Law of Evidence and its amendments, No. 30 of 1952, and its amendments under Amended Law No. 22 of 2017, published in the Official Newspaper, Page 200 , No 1108 ,On 17/5/1952

${ }^{4} 1$ Muhammad Rizk Ismail Abu Al-Foul, the authenticity of audiovisual means in evidence, Master's thesis, 2018, Faculty of Law, Yarmouk University, Jordan, p.52
} 
The availability of these conditions in the signature associated with the electronic record grants the record the evidentiary power granted to the regular bonds

Article (10) of the Law of Evidence defines a regular bond as "the bond which includes the signature of his issuer, his seal, or his fingerprint and does not have the capacity of an official bond "

Article (11) of the Law of Evidence states that the authenticity of the regular bond is for the concerned parties themselves, without the third parties having any authority to claim using this bond.

This helps that in case one party provides an electronic record associated with a protected signature the other party may deny either the electronic signature associated with this electronic record or the content of what is stated in the electronic record.

In the event of denying the signature, it is the responsibility of the party holding the electronic record to prove that this signature belongs to the one who is denying it. In the case of the denial of the content, the denier must prove the incorrectness of what is stated in this electronic record.$^{1}$

However, the electronic record associated with the protected signature can be subject to what is stipulated in Article $12 / 1$ of the Law of Evidence, which is that the electronic record -with a fixed date -has authenticity for other than the parties of the transaction .

As for the authenticity of the electronic record associated with the authenticated signature in encountering others, it shall be according to what is stipulated in Article (12/1) of the Law of Evidence, knowing that the date of the regular bond does not have authenticity over others on its date except since it has a fixed date, it has a fixed date according to the second paragraph of the same article in the following cases :

1. $\quad$ From the day that the notary public certifies it

2. From the day that its contents are confirmed in another document of officially fixed date

3. From the day it is indicated by a judge or a competent official

4. From the day of the death of one of those who have a fixed trace or acknowledgment in a bond, such as a handwriting, signature, seal, or fingerprint, or from the day that it becomes impossible for one of those to write or fingerprint due to an illness in his body .

We find that the evidence of writing cannot be fully applied on the electronic records, according to what is stated in the article, and that is because determining such a matter requires more electronictechniques than paper means . With reference to the judicial rulings, we find that the Court of Cassation approved (in its decision No. 255/2017) what the Court of Appeal had reached in its decision, that the Court of Appeal had approved that there was a previous dealing between the plaintiff (respondent ) and the defendant (appellant) since 2004, and the defendant (appellant) rented an area within the free markets hall at the Queen Alia airport, ${ }^{2}$

by referring to the electronic record which included that there are electronic negotiations between the two parties, the two parties had agreed on all the essential details regarding the limits of the rent and the rent allowance. ${ }^{3}$

We find that the legislator has graded in the evidentiary power of the electronic record in the two previous cases, despite the fact that they were granted the authenticity of the regular bond in evidence, but it grades and distinguishes between the two types in the evidentiary power, it grants the electronic record associated with authenticated signature the power of the official bond, although it does not rise to the degree of the official bond, and made the electronic record-associated with the protected signature- the authenticity of the regular bond, as its authenticity is limited to its parties, except in the event that it has fixed date, its authenticity will include the other parties .

The second requirement: the non-presumed authenticity for the electronic record

An electronic signature may be associated to the electronic record, but this is not sufficient to rely on the electronic record as an evidence of the claim, and thus it does not have any authenticity for proving because only denial of this record is adequate to destroy its authenticity before the judiciary .

So the electronic record is not binding, and this case will be detailed in the first sectionof this requirement under the title of electronic record associated with simple signature.

As for the second requirement, it discusses one of the most important rules on which the Jordanian Law of Evidence is based, which is the principle that it is impermissible to create evidence, that is, the debtor cannot create evidence to prove the validity of his claim, and the debtor cannot create evidence that would destroy a creditor's claim. ${ }^{4}$

If the principle of the evidence creation is not consistent with the logic of evidence, the creditor may create evidence of his debtor's acquittal, and the debtor may create evidence to be indebted with .

\footnotetext{
${ }^{1}$ 1Beesan Atif Al-Yassin, the Authenticity of Electronic Commercial Books in Jordanian Law, Master's thesis, 2010, Faculty of Law, Amman Arab University, Jordan, page 58

${ }^{2}$ Mohammad Abu Alfoul, Previous reference, page 61

${ }^{3}$ Decision no. 255/2017, Court of Cassation in its legal capacity, issued on 26/10/2017 see also decision no. 1604/20015 Court of Cassation in its legal capacity, issued on 31/12/2015 available on qarark website

${ }^{4}$ IssaGhassanRabadi, The Rules for Electronic Signature, 1st Edition, 2009, Dar Al-Thaqafa Publishing and Distribution, Amman ,Jordan, page 241
} 
However, the legislator excluded three cases from this rule, which are commercial books, private books anddocuments, and the principle of written evidence

They will be discussed in the second section under the title of electronic record created by one party

The first section: the electronic record associated with a simple signature

The legislator states in Article (17 / c), "In other than the cases stipulated in Paragraphs (A) and (B) of this Article, the electronic record bearing electronic signature shall have the same authenticity for the regular bond in countering the parties of the electronic transaction. In the event of denial, the burden of evidence falls on those who invoke using the electronic record.

We find through the article that the legislator finds a third authenticity for the electronic record, accordingly, it grants individuals the possibility to prove their claim through linking the electronic record to the electronic signature, which is called a simple electronic signature or a regular electronic signature, this type of signature is often used to the state the identity of the user, and in order for this user to abide by the contents of the data message, and some find that the judge has discretion in accepting the electronic record associated with this type of signature. ${ }^{1}$ In this case, this record shall have the authenticity of the regular bond and the legislator has indicated in the text of the same article the extent of authenticity granted to such an electronic record, that is, in the event that one of the parties holds to the electronic record, is it is sufficient for the other party to deny this record in order to destroy its authenticity.

The party who invokes using this electronic record as evidence in the lawsuit shall present to the judge what proves the authenticity of this electronic record, and that the signature was done in a reliable technical way. ${ }^{2}$ In other words, this electronic record, in case it is associated with a simple electronic signature, remains on hold for nondenial, because only denial is sufficient to destroy the authenticity, and the person holding it as evidence for the case must prove the validity of this electronic record

The second section: the unsigned electronic record

In the text of Article (17 / D) of the Electronic Transactions Law, "the unsigned electronic record shall have the authenticity of the unsigned documents in the evidence "

We find that the legislator according to this article grants to the unsigned electronic record the same authenticity adopted in by the Law of Evidence for unsigned documents.

With reference to the Law of Evidence, the legislator originally does not consider unsigned papers to be authentic , but following are three exceptions to grant authenticity to unsigned documents:

1. Commercial books .

2. Private books and documents

Which are fully regulated by the legislator in Chapter Three in the Law of Evidence

3. The principle of written evidence, which the legislator has organized in Article (30/1) of the Law of Evidence

First: the commercial books

Article (18) of the Law of Evidence stipulates that computer extracts authenticity for traders represent the commercial books

As the electronic commercial books are a representation of the use of the idea of electronic registration in relation to trader's accounting data. ${ }^{3}$

With reference to Article (15) of the Law of Evidence the legislator stipulates that "the traders' books shall not be an evidence against a non-trader. However, the data included in them on what the traders have stated are considered a base allowing the court to direct the supplementary oath to any of the parties "

So, we find that if the trader has an electronic record in which the commercial entries are saved, thenthis electronic record cannot be an evidence for the trader in the face of others on the grounds that it is evidence that he created himself, and the general principle is that it is not permissible to create evidence .

However, the other party "provided that he is not a trader" can rely on this electronic commercial record as evidence for him in the lawsuit. Yet, the court has the discretion to accept this electronic commercial record as evidence or refuse it, and in the event of acceptance, this electronic record will be considered as incomplete evidence in the case, this evidence is completed by the supplementaryoath that the court may address to one of the lawsuit parties

As for the text of Article (16) of the Law of Evidence, it includes the authenticity of the trader's mandatory books, as :

1. It is an evidence against its owner, whether it is legally organized or not

2. Suitable to be an evidence for its owner in the transactions pertaining to his trade if it is organized and there is a dispute between him and the trader

${ }^{1}$ Obaidat, Lawrence Mohammad, Proof of Electronic Documents, Edition 1, 2005, Dar Althaqafa Publishing \& Distribution , Amman, Jordan p. 159

${ }^{2}$ IssaRabadi, previous reference, p. 183

${ }^{3}$ Muayad Sultan NayefTarawneh, Commercial Books, Master's Thesis, 2015, Faculty of Law, Middle East University, Jordan, p. 107 
By applying these texts on the electronic commercial record, the record is considered a complete evidence, which does not require a supplementary oath. It can be provided by the trader's adversary, whether this adversary is trader or civilian, provided that this electronic record with which the trader saves his business is an electronic mandatory record, but the legislator does not stipulate that this electronic record is organized or not .

The Chamber of Commerce to which the trader belongs is the department concerned to determine how to organize the electronic commercial record. The second paragraph of the previous article refers to the only case in which the electronic trader's record is an evidence for him, which is: If the trader has an electronic commercial record that is mandatory organized in order to submit it as a complete evidence for him. However, the legislator requires a set of conditions in this record that can be drawn out from the same text of the article.

It is that the adversary of the trader in this case is a trader as well, and that the dispute subject of the lawsuit is related to his trade, so the trader cannot rely on the entries mentioned in his mandatory organized commercial record, to prove a matter outside the framework of his trade. In the event thatthe dispute is civil or commercial, but has nothing to do with his commercial activity, the trader cannot rely on this organized electronic commercial record as his evidence. ${ }^{1}$

As for the adversary to the trader, as a top priority for him is to rely on this mandatory organized electroniccommercial record as evidence to prove his claims. ${ }^{2}$

It is not worrying for the trader regarding that the legislator grants to the trader's adversary the possibility of relying upon the entries included in the electronic commercial record of the trader against him, whether it is an optional electronic commercial record or mandatory commercial electronic record and whether it is organized or not organized, because the trader can destroy this entry which is saved at the electronic record and to prove the contrary in all the evidence methods approved by the law, and he is not bound by the rule that (A written evidence is only destroyed by a written evidence "

-By referring to the court decisions, we find that the West Amman Court of First Instance decided in its decision No. $605 / 2019$ that the account statement that is the subject of the case is applicable to the description of the entry that is saved by electronic means as an electronic record, considering that the

court -through applying the regulations of the electronic transactions law on the lawsuit occurrences - mentioned that the legislator conduced the authenticity of written documents in evidence on the electronic record, and this is a violation of the general rule that a person is not allowed to create an evidence for himself, due to considerations of trust and the speed with which the business is characterized. ${ }^{3}$

decisions1. Decision no. 90/2019, West Amman Court of First Instance, issued on 18/03/2019 Decision no. 362/2019, West Amman Court of First Instance, issued on 29/05/2019, available on Qistas website

Second: Private Documents

The legislator stipulates in Article (16) of the Law of Evidence on the authenticity of the private books and documents, and considering that these documents are created from one party, the legislator does not grant them authenticity, as the text in the first paragraph of the same law states " the private books and documents are not considered as an authenticity for whom they are issued for"

However, in the second paragraph, the legislator excludes the case that the creditor explicitly mentions that he has collected his debt and explicitly states that he intended with what was written in these documents to act as a bond, in this case what the creditor has provided is considered as an evidence against him in countering his debtor

Accordingly, if the creditor saves in his electronic record that he has collected his debt, and he explicitly stated that he intended what he saved in this electronic record to replace the original bond, then the entry included in the electronic record prepared by the creditor is an evidence against him, and the debtor can prove the existence of this electronic record by all means of proof. $1^{4}$

\section{Third :The principle of evidence in writing}

The Law of Evidence defined in Article 30/1 the principle of evidence in writing as: Every writing issued by the adversary that would make the alleged contract existence close to possible .

It is clear that in order for the electronic record to be considered a principle evidenced in writing, this record must be available in the first place, and what is stated in the record must be issued by the adversary

or his representative, and that what has been mentioned makes alleged contract existence close to possible. ${ }^{5} \mathrm{When}$ these conditions are applied to the electronic document created and saved in the electronic record, we find that the first condition has been fulfilled, which is the presence of writing because the electronicdocument is saved in the

\footnotetext{
${ }^{1}$ 1Dr. AkramYamalki Commercial Law, A Comparative Study in Commercial Business, Trader, Store and Commercial Contracts, 1st Edition, 2010, Dar Al Thaqafa for Publishing and Distribution, Amman, Jordan, page 154

${ }^{2}$ DrAkramYamalky, Commercial Law, Previous reference, P 155

${ }^{3}$ Decision No.605/2019, West Amman Court of First Instance, issued on 24/09/2019 see other similar

${ }^{4}$ Marwa Abu Alola , Authenticity of Private Books and Documents in evidence, published on 23/05/2018, published on www.mohamah.net, date of visit 27/10/2019, time: 10:05

${ }^{5}$ BeesanAtefAlyaseen , Previous reference, page 89
} 
electronic record, But when we search for the second condition, which is that this writing should be issued by the adversary, we find that in electronic transactions it is proven that this electronic writing is issued by the adversary through an electronic signature

Thus, the lack of an electronic signature on the document makes it impossible to attribute the electronic document to the origin, even if it includes the name, and therefore, even if this electronic record is associated with the certificate and the judge is contented with it, such a matter can change the authenticity of the record to authenticity of electronic record associated with simple signature, in which denial will be sufficient to destroy its authenticity. ${ }^{1}$ Thus, we find that proof of the principle of evidence in writing cannot be visualized in the case of writing through electronic means .

\section{Conclusion}

At the end of the research in the authenticity of the evidence of the electronic record and the extent of the evidentiary power granted by the Jordanian legislator to the record, we came to a number of results and recommendations, the most important of which are :

\section{Results}

1. The legislator's adoption of a functional equivalent approach has enhanced in individuals the possibility of relying on the electronic record to save their transactions, and this has helped to facilitate the electronic transactions in general and the commercial activity in particular .

2. General rules are used to prove the authenticity of the electronic record, and the type of electronic signature associated with the electronic record determines the extent of the evidentiary power of this record .

3. The legislator did not regulate the authenticity of the copies of the electronic record, and did not also determine the evidential power of these copies .

4. The authenticity granted to the electronic commercial record is the same as the authenticity granted to the traditional commercial book, except that this electronic record must meet the necessary conditions in terms of saving it in the form in which it was created, not to modify it, and to be accessible at any time

5. It is not possible in all cases to apply the general rules of evidence contained in the Law of Evidence to prove using the electronic record, such as the case to make a fixed date for the electronic record, and the case of the principle of evidence in writing, as previously explained, because of the need for the existence of electronic techniques that control this issue, and commensurate with the nature of electronic record .

\section{Recommendations}

1. We recommend the legislator to regulate the authenticity of the copies of the electronic record, or even to refer to them in the Electronic Transactions Law, especially in light of the fact that the legislator has granted the electronic record in all its authenticity cases the same authenticity of the regular bond and graded among them in the evedentiary power only, and this matter cannot be applied on the copies of the electronic record .

2. We recommend that the legislator stipulates in details the method of denying what is stated in the electronic record, and proving the opposite of what is stated in it ,and not leaving the matter to the general rules for evidence, because the method of the denial of the content of the regular bond does not commensurate with the idea of denial of the content of the document or the entry in the electronic record, Comparison and subscribing cannot be carried out on the electronic record for example.

Rather, it is necessary to find technical and electronic methods that verify the validity of what is stated in the electronic record .

\section{References List}

First : Books

1. Dr. AkramYamalky, Commercial Law, a comparative study in business, trader and store and Commercial Contracts, 1st Edition, 2010, Dar Al Thaqafa for Publishing and Distribution, Amman, Jordan .

2. Dr. IssaGhassan Al-Rabadi, The Rules for Electronic Signature, 1st Edition, 2009, Dar Al-Thaqafa for publication and distribution, Amman, Jordan .

3. Dr. Lawrence Mohammad Abaidat, proof of electronic documents, 1st edition, Dar Al Thaqafa for .3 Publishing and Distribution, Amman, Jordan

\section{Second: Theses}

1. BeesanAtif Al-Yassin, the authenticity of the electronic commercial books in Jordanian law, Master's .

\footnotetext{
${ }^{1}$ Issa Rabadi, Previous reference, Page 264
} 
thesis , 2010, Faculty of Law, Amman Arab University, Jordan

2. Mohammad Rizk Ismael Al-Foul, the authenticity of the audiovisual means in evidence, Master's thesis, Faculty of Law, Yarmouk University, Jordan ,2018

3. Muayad Sultan NayefTarawneh, Commercial Books, Master's thesis, 2015, Faculty of Law, Middle East University, Jordan

\section{Third: Laws}

1. Electronic Transactions Law No. (15) for the year 2015 published in the Official Newspaper, page o. (5341) on 17/5/2015. (5292)

2. Jordanian Law of Evidence No. (30) of 1952, and its amendments pursuant to Amended Law No. (22) of ((2017), published in the Official Newspaper, page (200) No. (1108) on 17/5/1925

\section{Fourth: Judicial Judgments}

1. Judgement no. 255/2017, Court of Cassation in its Legal Capacity , issued dated 26/10/2017, available on qarark website

2. Judgement no.605/2019, West Amman First Instance Court , issued on 24/09/2019, available on qistas website

\section{Fifth : Electronic websites}

1. Marwa Abo El-Ola, Authenticity for private books and documents in evidence, published on 23/05/2018 Posted on the website, www.mohamah.net -Date of the visit (27/10/2019), 10:05 am. 